\title{
Saber geográfico e educação para cidadania: experiências de uma oficina sobre a questão indígena
}

\author{
Geographical knowledge and education for citizenship: experiences from a \\ workshop about the indigenous people issue
}

\author{
Amanda Christinne Nascimento Marques'; Vivianne de Sousa"
}

\section{RESUMO}

O artigo objetiva discutir a questão indígena por intermédio de uma oficina realizada para estudantes da disciplina Prática de Ensino I e II do curso de licenciatura em Geografia da Universidade Federal da Paraíba UFPB, assim como indicar textos de autores que podem subsidiar o professor em sua prática docente. Partimos para uma reflexão pautada em questionamentos: por que as sociedades não têm os mesmos traços culturais? Não veem o mundo da mesma maneira? Por que é tão difícil descolar a imagem do índio daquela anunciada no período de contato? Por intermédio da concepção de cultura demonstramos que ela é transmitida por gerações, mas também é ressignificada através do espaço-tempo. Discutir a questão indígena na sala de aula se coloca como desafio para o professor, tendo em vista que estamos lidando com um conteúdo envolto de muitos juízos de valor. Geralmente, eles são reproduzidos via livros didáticos e no próprio imaginário social que se construiu acerca do indígena ao longo do tempo. Nesta perspectiva, território e cultura passam a ser os temas fundamentais para o entendimento da questão indígena no Brasil.

Palavras-chave: Cidadania; Cultura; Questão Indígena; Território

\section{ABSTRACT}

The article aims to discuss the indigenous people issue through a workshop held for students of the discipline Teaching Practice I and II of the degree course in Geography of the Federal University of Paraíba UFPB, as well as to indicate texts of authors who can subsidize the teacher in their teaching practice. We start with a reflection based on the questions: Why societies do not have the same cultural traits? Do not they see the world in the same way? Why is it so difficult to take off the image of the indigenous people that was announced in the period of contact? Through the conception of culture we show that it is transmitted for generations, but it is also redefined through space-time. Discussing the indigenous issue in the classroom poses as a challenge to the teacher, given that we are dealing with content shrouded in many value judgments. Generally, they are reproduced via textbooks and in the very social imaginary that has been built on the indigenous over time. In this perspective, territory and culture become the fundamental themes for the understanding of the indigenous question in Brazil.

Keywords: Citizenship; Culture; Indigenous people issue; Territory

'Docente do Programa de Pós Graduação em Direitos Humanos - PPGDH/UFPB da Universidade Federal da Paraíba. Doutora em Geografia, pelo Núcleo de Pós-Graduação em Geografia-NPGEO da Universidade Federal de Sergipe. amandamarques.geografia@gmail.com ORCID: http://orcid.org/0000-0002-2642-988X

"Doutoranda em Sociologia pela Universidade Federal de Campina Grande. vivianne.uepb@gmail.com ORCID: http://orcid.org/0000$\underline{0001-5851-8660}$ 


\section{INTRODUÇÃO}

A temática indígena na escola é um conteúdo garantido pela lei $n^{\circ} 11.645$, de 10 de março de 2008, sendo sua inclusão obrigatória no currículo da rede oficial de ensino do país. A temática foi incluída na Base Nacional Comum Curricular - BNCC para educação infantil e ensino fundamental, aprovada em 2017. (BRASIL, 2017).

No ensino fundamental, ela aparece como competência específica ao componente de Geografia, notadamente no sétimo e nono ano. Entretanto, o próprio termo "povos indígenas", só é apresentado duas vezes nas habilidades concernentes às unidades temáticas.

No sétimo ano, a questão é evidenciada nos conteúdos referentes à formação territorial do Brasil e características da população brasileira. No nono ano ela se faz presente no conteúdo manifestações culturais na formação territorial.

Embora as garantias estejam presentes na legislação que nos regulamenta, é recorrente a pouca atenção dada ao tema, seja na dificuldade de se abordar a complexidade da questão, seja na compreensão social geradora de reprodução dos preconceitos que fundam o ideário da nação.

Via de regra, as práticas pedagógicas revigoram as imagens construídas a partir de visões formuladas nas situações de contato entre os europeus e as populações nativas. Essas imagens foram sendo cristalizadas ao longo do tempo e a condição do passado como elemento de aprisionamento do indígena coloca-o como figura de atraso e de hábitos primitivos.

Desse modo, a imagem do índio ao longo do processo histórico geralmente é remetida ao século $\mathrm{XVI}$, como se os grupos tivessem se revestido de um limbo em que o tempo-espaço deixasse de ser contínuo, para se manterem estanques como uma fotografia.

Inclusive, as fotografias, notadamente aquelas que encontramos recorrentemente nos livros didáticos, corroboram a construção do imaginário do índio do passado. Para demonstrar o diacrítico, os materiais didáticos apostam na pintura, cocar, flechas e arcos. O "ápice" da reprodução eivada de preconceito e dominação 
ocorre quando a imagem demonstra a integração de um "primitivo" com a natureza, aparentemente, intocada.

As aparências não se findam nas fotografias, faz-se importante mencionar também o dia 19 de abril, única data em que algumas escolas escolhem para tratar do tema. Nesse período, as crianças chegam em casa pintadas com tinta guache e uma folha de A4 impressa com a imagem de um índio e sua indumentária completa.

Embora no século XXI, ainda nos deparamos em sala de aula com comentários como:

- Nós vamos para a aldeia, mas eles vão estar nus?

- Eles são bravos?

- São índios de verdade?

Tomando como base esses pressupostos iniciais, intentamos neste artigo descrever os passos de uma oficina sobre a questão indígena que integrou as atividades do projeto PROLICEN[1]/UFPB (2017), intitulado: Produção do saber geográfico e formação para a docência, realizada para estudantes da disciplina Prática de Ensino I e II do curso de licenciatura em Geografia da Universidade Federal da Paraíba - UFPB, assim como indicar textos de autores que podem subsidiar o professor. Interessa-nos aqui realizar diálogo sobre o tema, demonstrando alguns procedimentos didáticos que podem ser adotados em sala de aula.

\section{PENSANDO A OFICINA}

A oficina foi organizada com base em plano de aula elaborado, em que destacamos o título da oficina, objetivos gerais e específicos, conteúdo programático, procedimentos metodológicos, recursos materiais, carga horária, público-alvo, resultados esperados e referências.

Intitulada: Território, Territorialidades e Direitos Humanos: a questão indígena, a oficina teve como objetivo analisar as dinâmicas territoriais dos povos indígenas no Brasil por meio dos marcos legais, imaginários sociais construídos a partir da figura do indígena e processos de luta por território. 
Estando com o plano e os conteúdos prontos, seguimos para o momento de pensar formas de abordagens e procedimentos didáticos que pudessem fomentar a criticidade dos participantes, momento em que tomamos como nota, as reflexões realizadas por Callai (2001) quando faz um debate sobre o papel da escola na construção da cidadania.

Era preciso, igualmente, que fossem demonstrados de maneira sintética, elementos fundamentais para o processo de luta pelo território indígena no Brasil e que se expressam na legislação vigente e nas práticas cotidianas de resistência desses povos.

Esse também era o momento de articular os conceitos operacionais da geografia, notadamente aqueles que pudessem subsidiar, na prática, movimentos multi escalares realizados pelos povos e que se materializam em eventos cotidianos.

Partimos, então, para estabelecer conexões entre o conceito de território e as palavras-chave: representações sociais, conflitos e cultura. A escolha, nos possibilitou geografizarmos o tema a partir da referida categoria de análise. Foi preciso, então, trabalhar com essas palavras-chave de maneira integrada para que fosse compreensível ao público o que nos propusemos trabalhar: futuros professores de geografia.

A argumentação e desenvolvimento deste texto partem da concepção de território como categoria que busca compreender as dinâmicas sociais por intermédio das práticas de dominação/apropriação. Para tanto, o autor central foi Raffestin (1993), sobremaneira quando afirma que o território "é um espaço onde se projetou um trabalho, seja energia e informação, e que por consequência, revela relações marcadas pelo poder, o espaço é a "prisão original" e o território é a prisão que os homens constroem para si" (RAFFESTIN, 1993, p. 28).

Desse modo, demonstramos como o poder foi sendo materializado nas dinâmicas territoriais dos povos indígenas. Os conteúdos foram organizados em uma linha do tempo, o que permitiu a compreensão da dinamicidade do espaço-tempo, assim como as diferentes periodizações que comportam o entendimento do tema. Em virtude da carga horária de 2 horas destinada à oficina, elencamos momentos 
representativos para entendimento da questão: 1500, 1850, 1930, 1970 e período atual.

O que significa dizer que não propomos esgotar o tema neste artigo, nem construir um texto com exaustivo referencial teórico. Interessa-nos apresentar um caminho possível de elucidação da temática e que possibilite reflexões futuras.

Cabe destacar ainda que as periodizações que denotam passagens de um tempo histórico para outro não ocorreram sem conflito ou resistência. Não podemos compreender tais periodizações como fissuras no tempo-espaço, como se essa relação se assemelhasse à mudança de um objeto de um lugar para outro. Cabe a nós demonstrar alguns registros no sentido de evidenciar alguns hiatos e/ou representações construídas sobre esses povos.

1500: período de contato/dominação

1850: Lei de Terras

1930: Teorias Raciais

1970: Emergência étnica

Período atual: Luta por demarcação territorial (MARQUES, 2015).

Elegemos cores que pudessem possibilitar ao leitor perceber gradações no espaço-tempo, assim como também demonstrar intensidades e/ou expressões de cada período. Fizemos a escolha por cores quentes, em virtude de nossa abordagem tomar como centralidade a questão da terra, elemento chave de reivindicação dos povos indígenas e que ainda não foi resolvida pelo Estado brasileiro.

Assim, como o calor emitido pelas cores, a terra demonstra intensidades materializadas em processos de lutas e mortes constantes no cotidiano dos povos indígenas, desde o período colonial.

As cores escolhidas na periodização de 1500 a 1850, são resultantes de misturas de cores primárias, conforme figura 1 a seguir. Elas foram utilizadas propositadamente para demonstrar os conflitos provenientes do processo de contato, ao tempo em que a própria cor marrom, remete a terra/território, elemento de centralidade em nossa discussão. 
Figura 1 - Modelo de linha do tempo para discussão sobre a questão indígena em sala de aula.

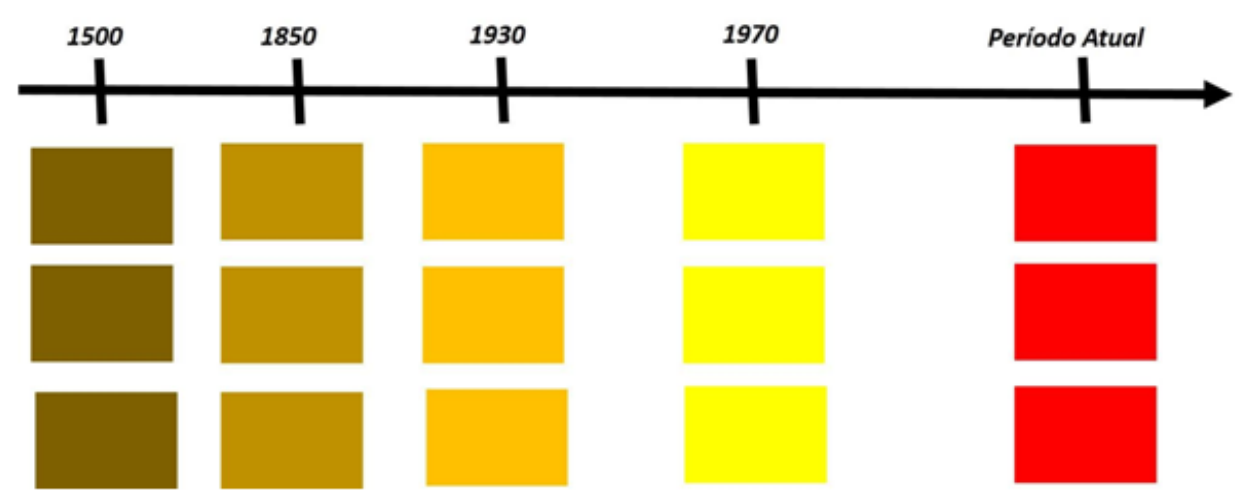

Fonte: Organização dos autores (agosto de 2018).

Iniciamos este texto fazendo relatos de como a imagem dos indígenas estão atreladas, sobremodo em sala de aula, a figuras e literatura que os colocam como elementos históricos estanques no tempo-espaço do período de contato. Desse modo, buscamos fotografias de indígenas na atualidade, ocupando diferentes espaços sociais: câmara de deputados, vereadores, prefeituras, universidades, aldeias e movimentos sociais.

Também almejamos utilizar imagens que nos possibilitassem perceber o indígena como sujeito social, sem arquétipos, adereços ou outro marcador social, como forma de buscar desconstruir o imaginário do índio do XVI.

Foram utilizadas imagens de indígenas que tiveram expressão nacional, a exemplo de Mario Juruna, primeiro deputado indígena eleito no Brasil e figura importante no processo de elaboração/aprovação da constituinte de 1988.

Apresentamos também fotografias daqueles que ocupam espaço no movimento indígena nacional e regional, tais como: esfera administrativa de municípios na Paraíba; universidades públicas, por meio da política de cotas Lei $\mathrm{n}^{\circ}$ 12.711/2012 (BRASIL, 2012) sancionada pelo presidente Luís Inácio Lula da Silva; exercício do papel de caciques em suas comunidades e lideranças jovens que no interior de suas aldeias e em espaços públicos assumem funções de protagonismo. (BRASIL, 2017). 


\section{PRÁXIS DA OFICINA}

Iniciamos a oficina organizando as cadeiras da sala em semicírculo e colocando as imagens de indígenas no chão para que os participantes pudessem visualizá-las em sua completude. A questão geradora desse momento foi: quem são os indígenas nas imagens?

Cada participante escolheu uma imagem, sendo que as primeiras fotografias escolhidas foram aquelas em que os traços diacríticos eram mais presentes, notadamente fenótipo e/ou localidade em que o indígena se encontrava.

À medida que foram se findando as imagens mais representativas do imaginário social, os participantes passaram a ter mais dificuldade para escolher. Percebemos, a partir das falas, que alguns critérios começaram a ser elegidos para realização da identificação, sendo eles: realização de atividades produtivas no campo; cor da pele; vestimenta. (Figura 2).

Figura2. Escolha de imagens de indígenas. Acervo particular dos autores (outubro de 2017).

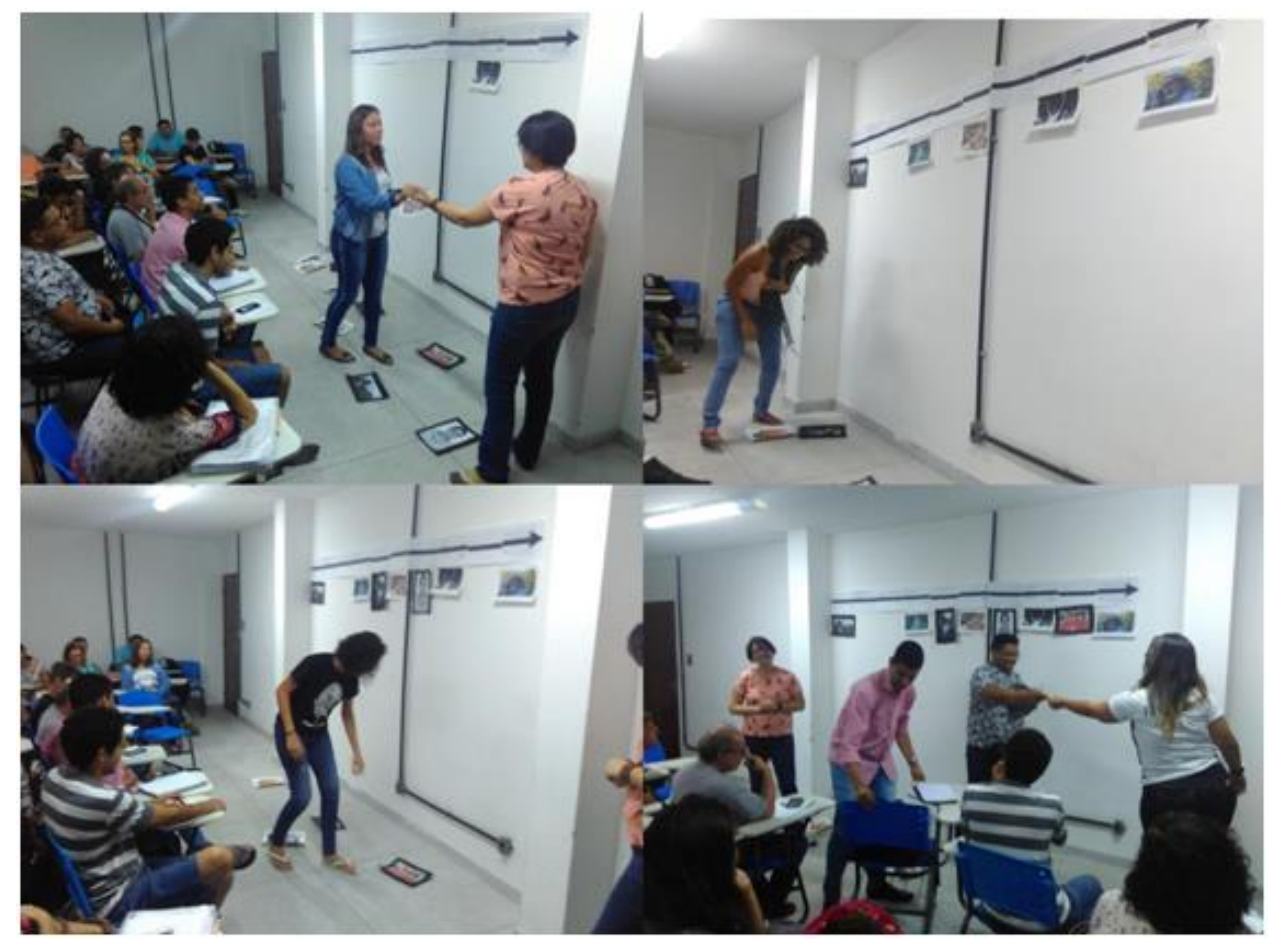

Segundo relatos, critérios de aproximação do que se caracteriza ser indígena no meio social foram sendo utilizados. Foi notória a associação entre a vinculação dos 
grupos ao meio rural, a busca por pinturas que pudessem aferir a alteridade, assim como a dificuldade de reconhecer um indivíduo com traços negroides.

Findada a escolha das imagens, buscamos desconstruir o imaginário coletivo aguçado durante o processo problematizador, pois:

Cabe à Geografia, nessa perspectiva, estudar como essas sociedades se organizam no espaço, como elas expressam suas culturas e como são refletidas aos "olhos dos outros" essas práticas. (MARQUES, 2009, p.34).

Partimos para uma reflexão pautada em questionamentos: por que as sociedades não têm os mesmos traços culturais? Não veem o mundo da mesma maneira? Por que é tão difícil descolar a imagem do índio daquela anunciada no período de contato?

Partimos então para explicar as diferenças apresentadas nos questionamentos, por intermédio da concepção de cultura, que na perspectiva de Claval (2001) trata-se de herança transmitida por gerações, mas que comporta dinamicidade e traduções por intermédio de relações de trocas sociais. Em sua concepção, cultura significa

[...] a soma dos comportamentos, dos saberes, das técnicas, dos conhecimentos e dos valores acumulados pelos indivíduos durante suas vidas e, em outra escala, pelo conjunto dos grupos de que fazem parte. A cultura é herança transmitida de uma geração a outra. Ela tem suas raízes num passado longínquo, que mergulha no território onde seus mortos são enterrados e onde seus deuses se manifestaram. Não é portanto um conjunto fechado e imutável de técnicas e comportamentos. Os contatos entre povos de diferentes culturas são algumas vezes conflitantes, mas constituem uma fonte de enriquecimento mútuo. A cultura transforma-se, também, sob efeito das iniciativas ou das inovações que florescem no seu seio (CLAVAL, 2001, p. 63. Grifos nossos).

Considerando as reflexões do autor, demonstramos que a cultura é transmitida por gerações, mas também é ressignificada através do espaço-tempo. Portanto, dinâmica e resultante de interações sociais.

Discutimos que não nos cabe conceber a imagem do índio por intermédio de nossas moralidades, ao tempo em que as próprias imagens apresentadas no início da oficina, são representativas da diversidade e alteridade desses povos.

Utilizamos como exemplo os critérios atuais utilizados pela Fundação Nacional do Índio - FUNAI, Estatuto do Índio,para identificar um indígena, que são baseados 
em sua autodeclaração e no reconhecimento desse indivíduo como integrante de uma coletividade pelo seu grupo de origem. (BRASIL, 1989).

Desse modo, tais coletividades remetem a traços étnicos que são reelaborados pelos grupos indígenas por gerações. Todo indivíduo que se identifica como indígena tem uma vinculação com um grupo étnico e isso se anuncia pela forma como esses indivíduos se apresentam. Geralmente o nome do indígena é pronunciado junto com a etnia a qual é pertencente.

- Sou Maria Potiguara

- João Tabajara

- Francisca Xucuru

- José Guarani

Embora o critério da autoidentificação seja utilizado por instituições como o Instituto Brasileiro de Geografia e Estatística - IBGE e a Fundação Nacional do Índio FUNAI e estejam amparados nos instrumentos legais, como a Constituição de 1988 e a Convenção 169 da Organização Internacional do Trabalho e Estatuto do Índio (lei 6.001/73), eles são pouco acessados no meio social, prevalecendo construções eivadas de concepções pré concebidas. (BRASIL, 1973).

Seguimos, então, para o segundo elemento problematizador: A que se vincula tal imaginário sobre o indígena? Momento em que nos remetemos à linha do tempo (figura 3) para demonstrar elementos inseridos em uma periodização que ratificam e reproduzem esses imaginários.

Durante o período de contato estima-se que a população indígena era superior a 1 milhão de habitantes (FAUSTO, 2000). Do litoral ao sertão, os indígenas foram sendo gradativamente incorporados como mão de obra e sendo dizimados pelos europeus que almejavam a conquista das terras do até então "Novo Mundo".

As principais referências do período foram escritas por viajantes que descreviam as belezas cênicas do país, ao tempo em que apresentavam uma leitura dúbia sobre esses povos. Para uns, bons selvagens, para outros primitivos e agressivos. 
Exemplos dessas narrativas estão presentes em Hans Staden (1974) e Américo Vespúcio (2003). O primeiro viveu com os Tupinambás descrevendo os rituais de antropofagia e o segundo sobre a chegada de tripulação europeia à Baia de Acejutibiró ou Acajutibiró, atual município de Baia da Traição, Estado da Paraíba.

Inclusive a mudança do topônimo ocorreu em virtude de um evento ocorrido entre os portugueses e os Potiguara. Segundo literatura, os indígenas capturaram tripulantes da expedição e realizaram ritual de antropofagia.

Figura 3 - Periodização sobre a questão indígena.

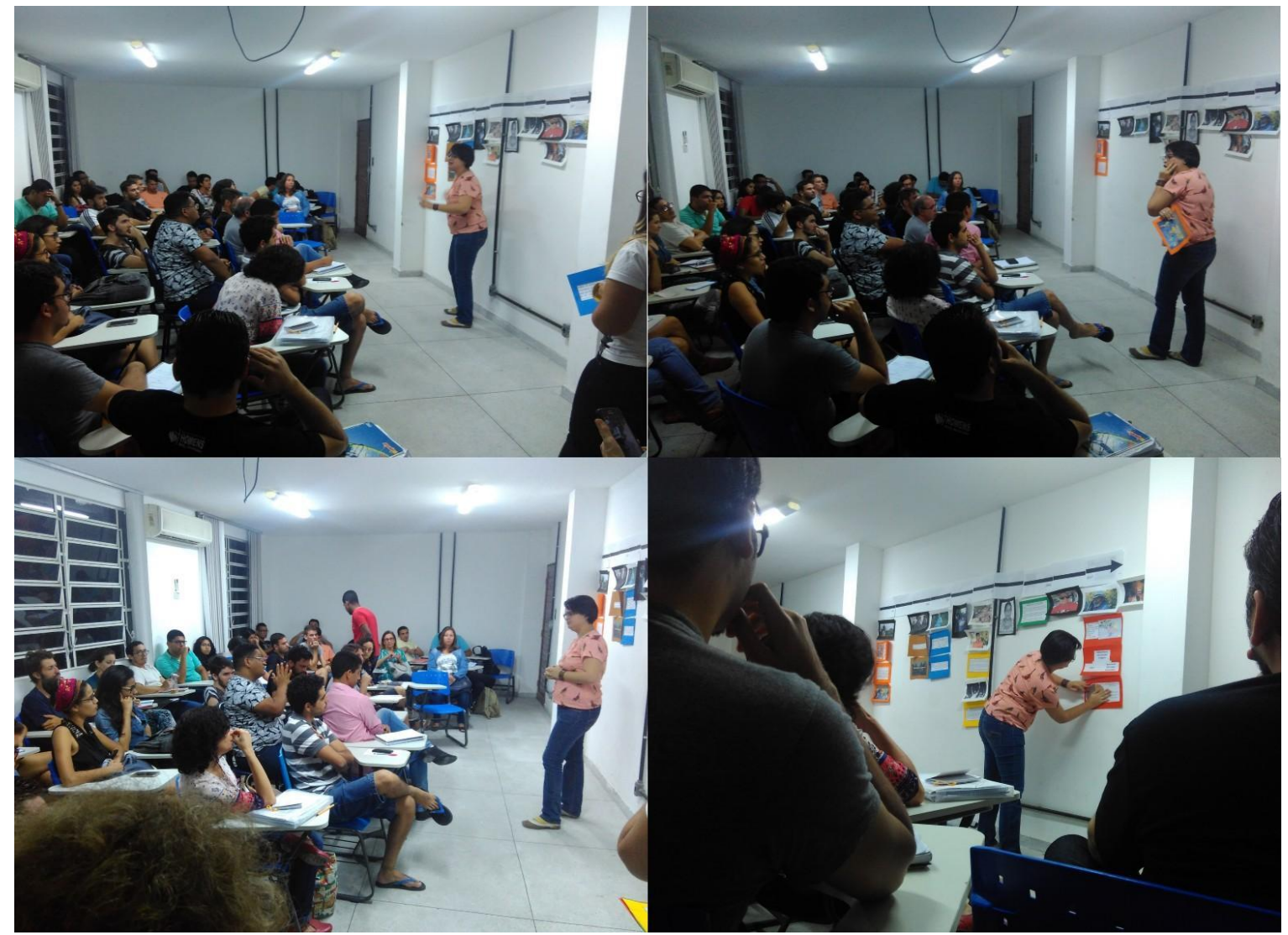

Fonte: Acervo particular dos autores (outubro de 2017).

As divergências encontradas na literatura de viagem reforçaram princípios morais que avigoraram as diferenças culturais entre o "eu" e o "outro" (TODOROV, 2003; MARTINS, 1997). Elas reforçaram o exercício do poder dos europeus que passaram a justificar seu domínio sobre o território por meio de relações etnocêntricas e eurocêntricas que colocavam o indígena numa condição de inferioridade. 
Desse modo, os povos que tinham costumes distintos foram objeto de curiosidade, ao tempo em que a referida literatura produziu representações sociais e ambientais como estratégia de manutenção hierárquica em relação ao "outro" indígena. Tais estratégias de dominação, são designadas por Chauí (1989), como mito fundador:

maneira necessária pela qual os agentes sociais representam para si mesmos o aparecer social, econômico e político, de tal sorte que essa aparência (que não devemos simplesmente tomar como sinônimo de ilusão ou falsidade), por ser o modo imediato e abstrato de manifestação do processo histórico, é o ocultamento ou a dissimulação do real (CHAUÍ, 1989, p.3).

As possibilidades de análise do recorte referente à questão indígena no século XVI é vasta, indicamos como leitura complementar trabalhos de Cunha (1992), Martins (1997), Raminelli (1996), Mendonça (2002), Fernandes (2003), Fausto (2000), Ribeiro (1995) e Marques (2006).

Se as representações acerca dos povos indígenas se colocam como fruto da construção de mitos fundadores, a temática pulsa no século XIX, por meio da implementação da Lei de Terras de 1850 que se caracteriza como mote das relações desses povos com a terra. Essa lei beneficiou grandes proprietários, promovendo a legalização da apropriação de espaços tradicionalmente ocupados pelos povos indígenas no Brasil, por meio de compra.

Muitos grupos, ao longo desse processo, já haviam sido expulsos de suas terras de origem, caso ocorrido com o povo Tabajara no Litoral Sul (MARQUES, 2015; MURA et al. 2015), assim como foram sendo incorporados por meio de políticas que promoviam assimilação e integração à sociedade de classes, como moradores de condição, posseiros e arrendatários.

No caso dos indígenas situados na região Nordeste, sua força de trabalho foi destinada para atividades monocultoras e a pecuária, com predominância da cana de açúcar, no litoral e criação de gado, no sertão. Em virtude das ações desterritorializantes mencionadas, muitas famílias passaram a ser identificadas como originária de antigos "caboclos, misturados, mestiços, aculturados, camponeses e/ou "objeto de contaminação" (AMORIM, 1970; MOONEN, 1992; ARRUTI, 1995; PERES, 
2000; BARBOSA Jr., 2002; OLIVEIRA, 2004; PALITOT, 2005; MARQUES, 2009; MURA et. al, 2015).

Os referidos termos promoviam a apropriação social que refletiam imaginários de que no Nordeste não havia mais indígenas, mas apenas pequenos núcleos de descendentes "misturados" a sociedade envolvente. Como os núcleos não comportavam a quantidade de indígenas que estavam sendo retirados de suas terras, muitas famílias estabeleceram trajetórias migrantes para os grandes centros urbanos.

Tais denominações foram fruto de uma construção social, provenientes de teorias raciais, elas traziam a questão da mestiçagem como um elemento de atraso para a nação, ao tempo em que propunham um branqueamento evolutivo, por meio da imigração europeia.

Ainda no século XIX, esse conceito foi incorporado ao discurso das Ciências Sociais, no qual, por meio de uma leitura etnocêntrica, os estudos sobre raça passaram a atuar como uma justificativa para o processo "civilizador" que explicava a inferioridade de alguns grupos étnicos, a exemplo dos negros e indígenas (MARQUES, 2015).

As primeiras discussões feitas sobre a miscigenação como elemento positivo na construção identitária da nação brasileira foram realizadas por Freyre (2003), por meio da obra "Casa Grande \& Sensala". Nela, a mistura/miscigenação é avaliada como elemento de relações harmoniosas e romantizadas entre senhores e escravos, geradora da ideia de democracia racial. (SCHNEIDER, 2013).

Somente durante o século XX esse conceito foi questionado, sobretudo com os debates acerca dos mitos que fundavam o pensamento social brasileiro, a exemplo do mito da democracia racial, cuja reflexão foi desenvolvida por autores como Roger Bastide, Abdias Nascimento, Mário de Andrade, Lilian Schwarcz, Florestan Fernandes e Kabenguele Munanga. (MARQUES, 2015).

A intensão do Estado em promover a integração dos povos indígenas no Brasil, fica expressa no século XX. Período em que sua situação jurídica é propagada na Lei 6.001, de 19 de dezembro de 1973, denominada de Estatuto do Índio. Em seu primeiro artigo diz: 
Art. $1^{\circ}$ Esta Lei regula a situação jurídica dos índios ou silvícolas e das comunidades indígenas, com o propósito de preservar a sua cultura e integrá-los, progressiva e harmoniosamente, à comunhão nacional. (BRASIL, 1973).

Aos povos indígenas foram destinados o poder tutelar do Estado por intermédio da FUNAl, que promoveu uma política de assimilação, agenciando e controlando os territórios que ainda não haviam sido esbulhados, bem como promovendo lógicas de integração por meio de concessões de atividades de trabalho indígena nas aldeias e arrendamentos (PERES, 2000). Essa era uma forma de "resolver" a omissão do Estado brasileiro sobre a questão.

Até 1970, as tentativas de "silenciamento" desses povos reproduziam a imagem de inferioridade e marginalização do indígena. Entretanto, os princípios de integração surtiram efeito contrário entre os indígenas que passaram a realizar movimentos locais de reivindicação territorial e identitária.

Esses grupos originaram um movimento durante as décadas de 1970 até os dias atuais. Segundo Arruti (1995), (2002) e (1997), as populações indígenas e negras vêm se mobilizando político e culturalmente pelo reconhecimento de suas terras, sendo esse período descrito e denominado pelo autor de Emergência Étnica.

Para os indígenas, a emergência étnica não é só explicada a partir das mudanças das ações dos povos, mas sobretudo porque elas representam um significado próprio de recuperar as relações de proximidade entre indígenas de outras etnias.

Uma das formas de reconstituição das causas indígenas foram as relações de proximidade por parentesco de descendência ou político entre índios de diversas aldeias. Arruti (1995) cita o exemplo dos índios Pankararús em Pernambuco, que ajudaram muitos grupos étnicos a reivindicarem suas identidades e legitimidade indígena, a exemplo dos índios Tuxá e os Fulni-ô.

Segundo o autor, "existe um circuito regional de empréstimos culturais e apoio político entre aldeias" (ARRUTI, 1995 p.44). Um dos "empréstimos culturais" pontuado diz respeito à dança ritual do Toré, que é vista pelos índios como uma expressão obrigatória de indianidade e constituída de vários significados. 
Sobre esse assunto, Marques (2009, p.63) faz uma reflexão sobre o povo Potiguara, localizado no litoral norte paraibano:

Podemos citar o exemplo dos índios Potiguara da Terra Indígena (TI) de Monte Mor, onde o território que foi retomado há alguns anos [...] é pleiteado por índios, usineiros e posseiros. Uma das formas mais presentes de representar a indianidade e o direito à terra que foi possuída por seus ancestrais, é dançar o toré quinzenalmente. A dança foi ensinada pelos índios mais velhos de Monte Mor e os índios de outras duas Terras Indígenas Potiguara.

Nesse contexto, percebemos duas formas de constituição da imagem do índio, no período atual. A primeira referente à sociedade brasileira e a segunda, relativa aos grupos indígenas, estando inseridos nessa segunda forma de constituição, pesquisadores e pessoas que apoiam o movimento de luta pela causa indígena (MARQUES, 2006).

Figura 4 - Territorialização do Povos Indígenas no Brasil.

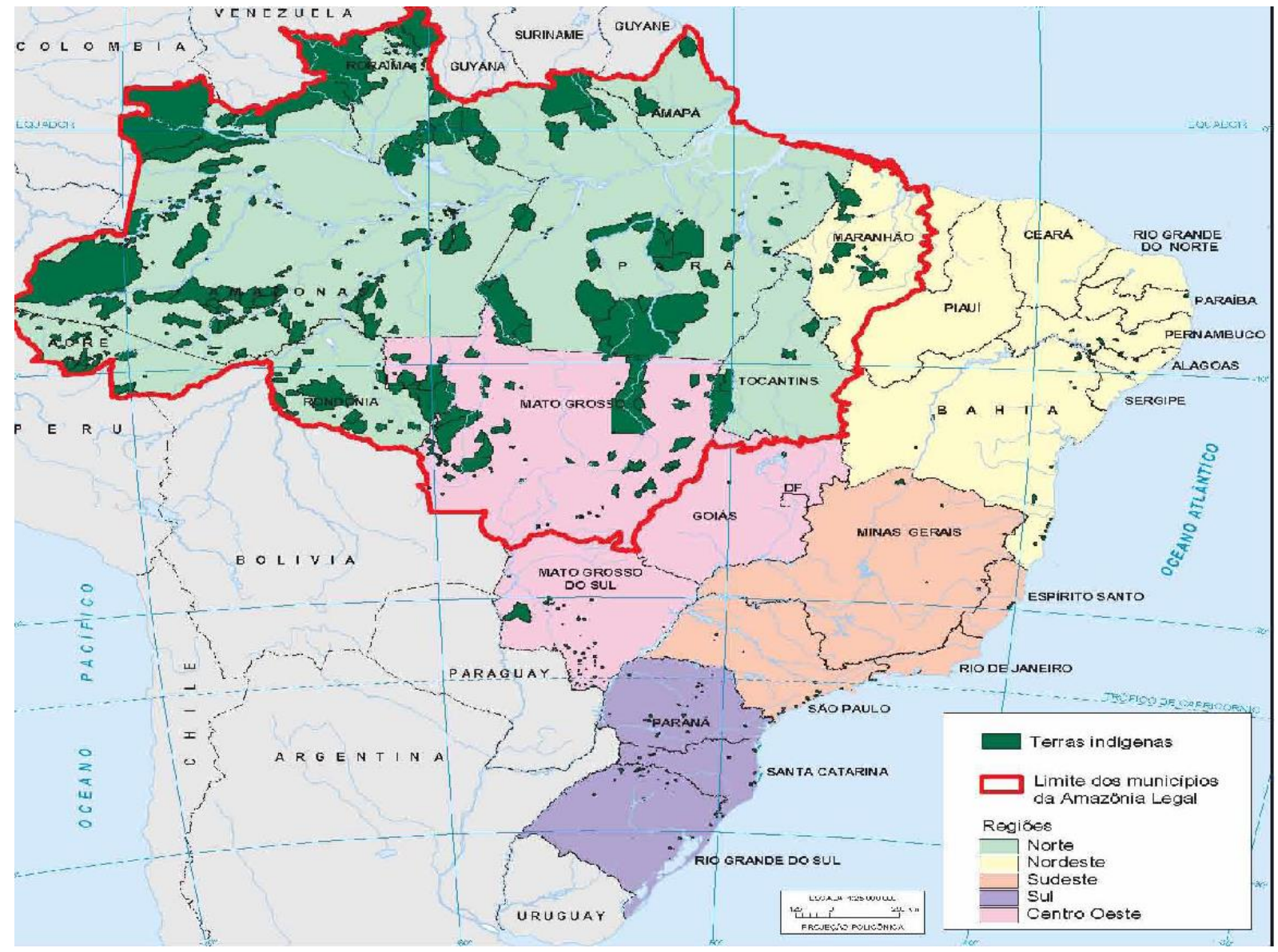

Fonte: IBGE (2005). 
Pensar a questão indígena no período atual, significa buscar nos processos históricos desterritorializantes, suas formas de resistência. São 817.963 indígenas no Brasil, distribuídos em aproximadamente 398 etnias. (Figura 4).

A maioria desses grupos estão localizados na região Norte do país (+50\%), seguido da região Centro - Oeste (18\%), Nordeste (16\%), Sudeste (7\%) e Sul (4\%). (IBGE, 2010).

As principais demandas do movimento indígena são: demarcação territorial e reconhecimento étnico. Com vistas ao estabelecimento das pautas reivindicatórias dos povos, existem articulações e coletivos que buscam ocupar espaços de representatividade no país, destacando-se a Coordenação das Organizações Indígenas da Amazônia Brasileira - COIAB e a Articulação dos Povos Indígenas do Nordeste, Espírito Santos e Minas Gerais - APOINME.

De acordo com Oliveira (2004), o movimento indígena apresenta nuances regionais, em virtude das especificidades dos processos de territorialização. Enquanto na região Norte, os indígenas detêm parte dos seus territórios, nichos ecológicos e colocam como bandeira central a questão de preservação ambiental em seus territórios; na região Nordeste, os territórios foram ocupados pelos colonizadores, colocando esses grupos em confrontos cotidianos frente à questão fundiária.

Tomando como base a situação administrativa das terras indígenas no Brasil (2016), apresentados pelo Conselho Indigenista Missionário - CIMI e organizados na figura 5 a seguir, $80 \%$ do montante de terras estão por identificar ou sem providências. Das 1.113 terras indígenas reconhecidas, apenas $398(35,7 \%)$ tem seus processos administrativos finalizados.

No Estado da Paraíba, por exemplo, são identificados dois povos que estão territorializados no litoral, sendo eles: Potiguara, situados na porção norte, entre os municípios de Baia da Traição, Marcação e Rio Tinto; e Tabajara, situados ao sul do estado, entre os municípios do Conde, Alhandra e Pitimbu. 
Figura 5 - Situação Administrativa das Terras Indígenas no Brasil (2016). Fonte: Conselho Indigenista Missionário - CIMI

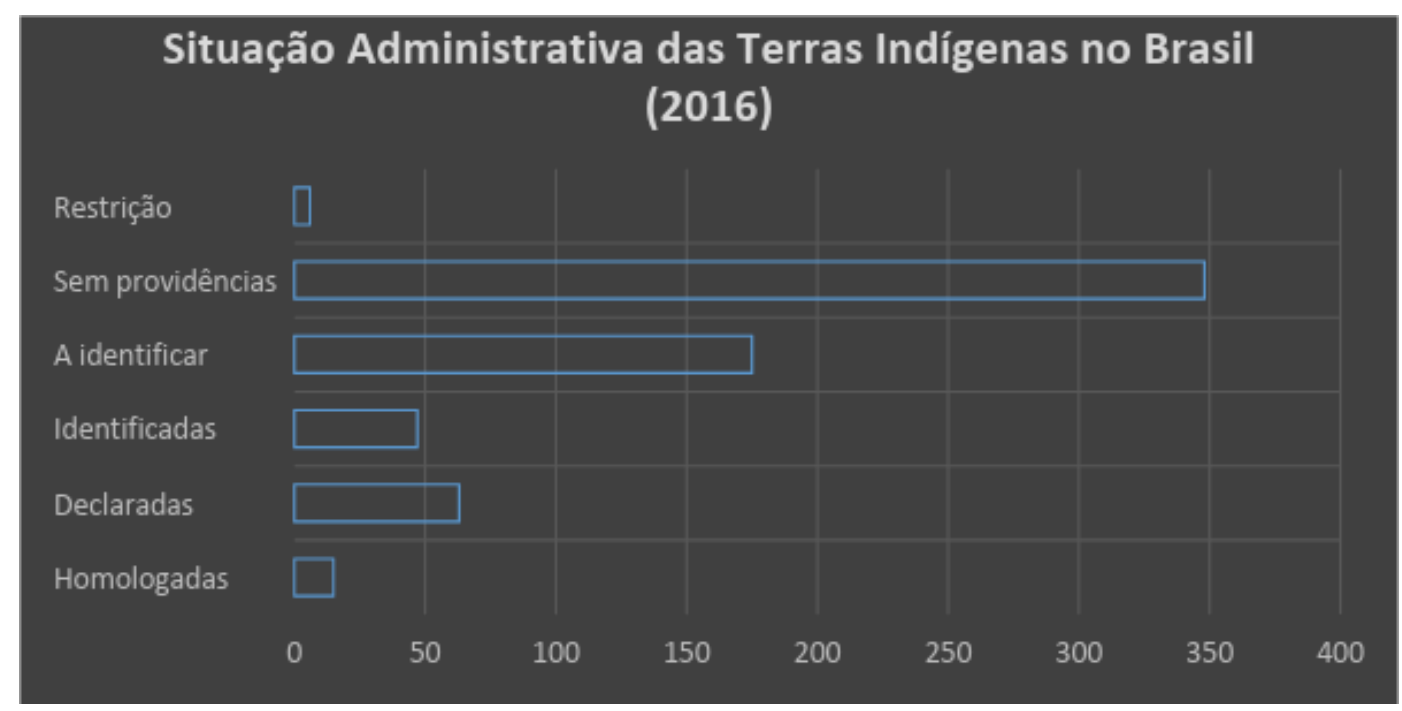

Fonte: Elaboração dos autores (agosto de 2018).

Os Potiguara estão organizados em 32 aldeias indígenas e têm população de aproximadamente 13.000 indígenas. Embora tenham perdido grandes porções territoriais em virtude do processo de colonização, esse povo é reconhecido nacionalmente por se manterem nos recortes da Paraíba, no mesmo lugar desde 1500. (MARQUES, 2009).

Os Tabajara tiveram seu processo de emergência étnica em 2006, momento em que famílias tradicionais do antigo aldeamento da Jacoca reclamaram sua identidade étnica. Atualmente contabiliza-se aproximadamente 1.500 indígenas que residem nos municípios do Conde, Alhandra, Pitimbu e João Pessoa. (MARQUES, 2015).

Embora com processos de luta distintos, que podem ser conhecidos por meio dos trabalhos de Marques (2006, 2009, 2015), Mura et al. (2015) e Palitot (2009), esses povos continuam reivindicando direitos para terem salvaguardados seus territórios de origem.

O avanço dos processos emergentes também traz um lado de violência e impunidade. Os últimos anos de mandato (2014 a 2016) da presidenta Dilma Rousseff foram de aumento da insegurança nas terras indígenas, conforme observação na figura 6. Ao tempo em que os povos avançaram em suas demandas também houve o 
processo de expansão do agronegócio no Brasil fomentado pelas frentes conservadoras instaladas. As bancadas da bala, boi e bíblia promoveram um verdadeiro campo de guerrilha no país.

Figura 6 - Assassinatos de Indígenas no Brasil (2013-2015). Fonte: Conselho Indigenista Missionário - CIMI.

\section{Assassinatos de Indígenas no Brasil (2013- 2015)}

160

140

$138 \quad 137$

120

100

80

92

60

58

60

60

60

51

60

53

40

37

43

20

0

$2013200420052006200720082009201020112012 \quad 2013 \quad 20142015$

Fonte: Elaboração dos autores (agosto de 2018).

Destacam-se as frentes de expansão do Centro-Oeste para o Norte, e do Maranhão, Tocantins e Bahia - MATOPIBA.

A primeira frente descrita se dá pela expansão da produção de soja e pecuária bovina. Nessa frente, são contabilizados os maiores números de assassinatos de indígenas no país. Podemos visualizar na figura 7 a seguir imagem produzida pelo CIMI e que denuncia esses casos.

Já a região do MATOPIBA, que engloba 337 municípios, tem o propósito de promover frentes de expansão do agronegócio por intermédio da agricultura mecanizada e grande complexos irrigados em áreas de cerrado que compreendem a 73 milhões de hectares dos Estados do Maranhão, Tocantins e Bahia. (IPEA, 2018). 
Figura7 - Agronegócio associado ao processo de violência contra os povos indígenas no Brasil.

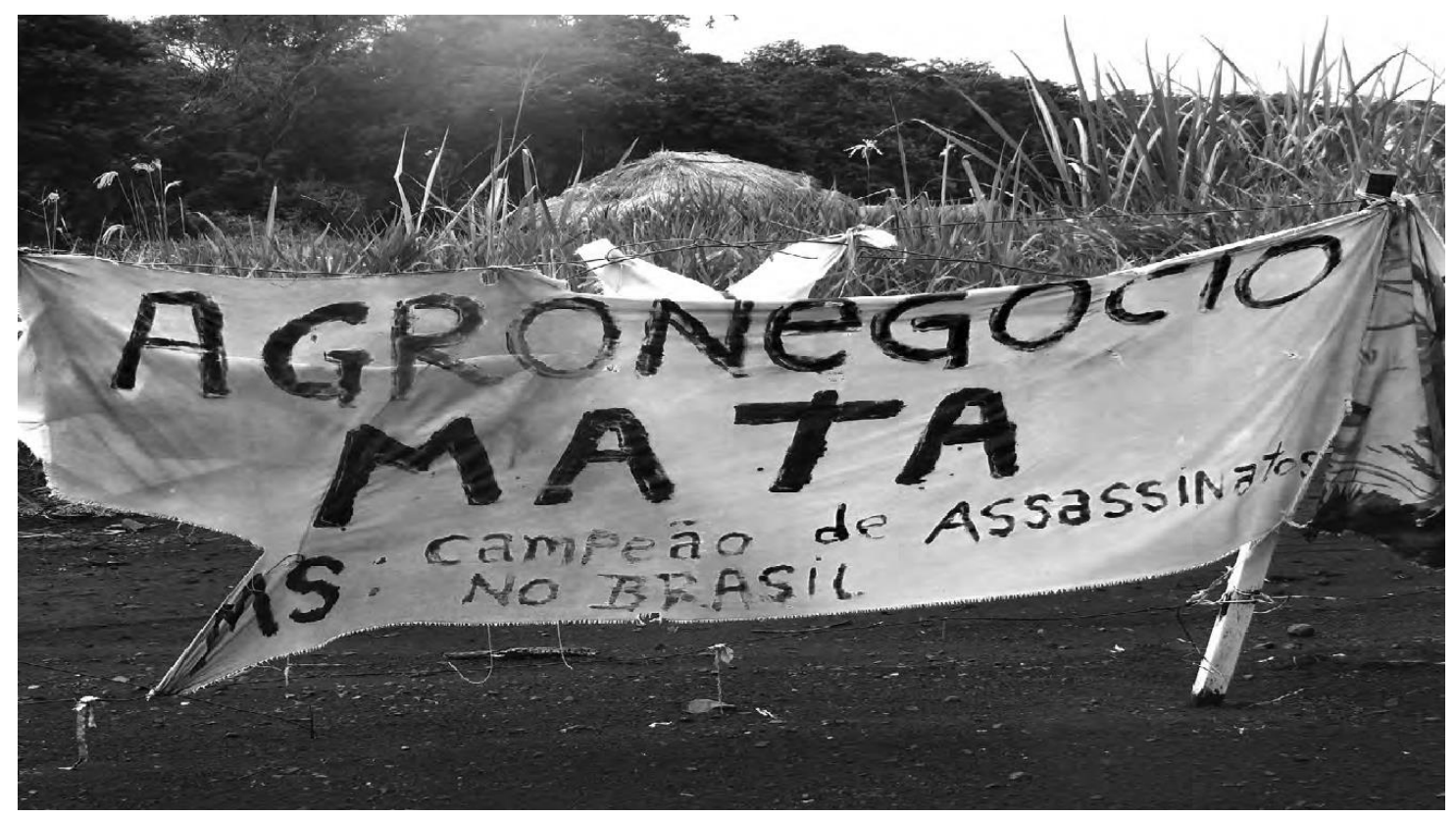

Fonte: CIMI (2015).

Essa frente de expansão tem promovido atração de grandes proprietários de terra das regiões sul, sudeste e centro-oeste, assim como tem promovido conflitos de interesses nas 35 Terras Indígenas que estão incluídas no referido projeto de expansão. (IPEA, 2018) Como pudemos perceber ao longo da escrita deste artigo, o estudo da questão indígena comporta complexidades emolduradas por relações de poder com facetas multiescalares e em nuances que se materializam no espaçotempo.

Os referencias acessados pelos professores ainda são limitados a utilização do livro didático, fatores como a disponibilização dos materiais on line e a falta desses referenciais nas escolas, impossibilitam o acesso. Diante disso, elencaremos a seguir indicações que podem ser acessadas e que subsidiarão o trabalho docente.

\subsection{Referências bibliográficos que versam sobre a questão indígena}

a) Livros e Cartilhas Didáticas: 
BARCELLOS, L; FARIAS, E; FONSECA, I; FLORES, E; RODRIGUES, J. M. Diversidade

Paraíba: indígenas, religiões afro-brasileiras, quilombolas, ciganos. João Pessoa: GRAFSET, 2014.

BENJAMIM, R. E. C. O Brasil Indígena: história e cultura dos povos indígenas do Brasil. João Pessoa: GRAFSET, 2010.

GERLIC, S; ZOETTL, P. A. (orgs.) Índios na visão dos índios: Potiguara Salvador: Thydêwá, 2011.

b) Autores que versam sobre a questão indígena na Paraíba

AMORIM, P. M. de. Índios Camponeses: os Potiguara de Baía da Traição. (Dissertação de Mestrado em Antropologia Social) Rio de Janeiro: UFRJ/Museu Nacional, 1970.

AZEVEDO, A. L. L. de. 'A terra somo nossa': uma análise de processos políticos na construção da terra potiguara. Rio de Janeiro. Mestrado em Antropologia Social - MNUFRJ,1986.

BARBOSA JUNIOR, F. de S. Os caboblos de Monte-Mór: identidade e resistência Potiguara. João Pessoa (Especialização em Direitos Humanos), UFPB, 2002.

BAUMANN, T. de B. Relatório Potiguara. Rio de Janeiro: Fundação Nacional do Índio. 1981.

LIEDCKE, A. R. Territorialidade e Identidade Potiguara: a atuação do Ministério Público Federal em contextos de lutas pelo reconhecimento dos direitos indígenas no vale do rio Mamanguape, Litoral Norte, PB. (Dissertação de Mestrado em Sociologia) CCHLA/ UFPB: João Pessoa, 2007.

MARQUES, A. C. N. Imagens do Território Potiguara: conflitos e resistências na aldeia Três Rios, Marcação - PB. (Monografia de Graduação em Geografia), João Pessoa: UFPB, 2006.

MARQUES, A. C. N. Território de Memória e Territorialidades da Vitória dos Potiguara da aldeia Três Rios/ Amanda Marques - João Pessoa, 2009.

MARQUES, A. C. N. Fronteira étnica: Tabajara e comunidades negras no processo de territorialização do Litoral Sul paraibano. Tese de Doutorado em Geografia. Aracajú: Universidade Federal de Sergipe, 2015. 
MOONEN, F. \& MAIA, L.M. Etnohistória dos Índios Potiguara: ensaios, relatórios e documentos. João Pessoa: PR/PB-SEC/PB, 1992.

MURA, F; PALITOT, E; MARQUES, A. Relatório Tabajara: um estudo sobre a ocupação indígena no litoral sul da paraiba. João Pessoa: UFPB, 2015.

PALITOT, E. M. Os Potiguara da Baía da Traição e Monte-Mór: história, etnicidade e cultura. João Pessoa: UFPB (Mestrado em Sociologia), 2005.

PERES, S. Os Potiguara de Monte-Mór e a Luta pelo Reconhecimento de seu Território. In: Carlos Alberto Ricardo. Povos Indígenas no Brasil (1996-2000), São Paulo: Instituto Sócio Ambiental, 2000.

\subsection{Legislações que fazem referência aos povos indígenas}

c) Lei n 6.001 de 19 de dezembro de 1973 - Estatuto do Índio

d) Constituição Brasileira de 1988 Art. 231, Art. 232, Art. 67

e) Decreto 1.775 de 08 de janeiro de 1996

f) Lei $n^{\circ} 11.645$, de 10 de março de 2008

g) Lei 10.639, de 9 de janeiro de 2003

\subsection{Filmes}

a) Martírio. Duração (2h40min). Relata o processo de luta pela terra no Brasil, tomando como base a violência sofrida pelos Guarani-Kaiowá, situados na região centro-oeste do país.

b) Corumbiara. Duração (2h00min). Relato massacre de indígenas ocorrido no estado de Rondônia em virtude de conflitos com fazendeiros de gado da região.

c) Terra Vermelha (1h40min). Discute a questão da terra Guarani-Kaiowá demonstrando trajetórias de ocupação das terras tradicionais, conflitos com grandes proprietários de terra e relações de trabalho indígenas.

d) O povo brasileiro (vol.1 e 2). Documentário baseado na obra de Darcy Ribeiro que objetiva discutir os traços étnicos de formação do povo brasileiro 


\subsection{Sítios contendo informações básicas para Pesquisa}

www.funai.gov.br (Fundação Nacional do Índio)

www.isa.org.br (Instituto Socioambiental)

www.cimi.org.br (Conselho Indigenista Missionário)

\section{PARA NÃO FINALIZAR...}

Discutir a questão indígena na sala de aula se coloca como desafio para o professor, tendo em vista que estamos lidando com um conteúdo envolto de muitos juízos de valor. Geralmente, eles são reproduzidos via livros didáticos e no próprio imaginário social que se construiu acerca do indígena ao longo do tempo.

Esses discursos, ao expressarem as imagens dos índios através dos corpos nus disponíveis, de hábitos culturais, da antropofagia, da falta de leis, nos fazem pensar que possivelmente imperaram dois fatores importantes, ou seja, duas constantes ideológicas que referendaram a conquista e afirmaram a imagem do índio como tal. O primeiro fator é o território, visto como uma fonte de recurso, exploração e expansão geográfica, pois o ouro, as belezas naturais, as paisagens descritas e o patrimônio hídrico estão presentes nas narrativas e são vislumbradas como "terras sem dono". E o segundo, a cultura indígena, vista com inferioridade, bem como imaginada de forma primitiva e em possível estado de "salvação".

Nesta perspectiva, território e cultura passam a ser os temas fundamentais para o entendimento da questão indígena no Brasil. As relações sociais demonstradas com a periodização que elegemos na oficina, deixam visíveis a presença da identidade indígena, bem como sua imagem enquanto grupo social etnicamente diferenciado que se dá por meio diferentes formas de resistência.

Contatamos na oficina que houve dificuldade dos participantes em identificar os indígenas. As escolhas prioritárias eram àquelas em que se apresentavam marcadores sociais de diferença como pinturas, atividade realizada e traços fenótipos. Atribuímos tal dificuldade tomando como base os relatos dos próprios participantes, 
que afirmaram que existe um imaginário social que se construiu em torno desses povos.

Apesar da questão indígena estar amparada pela Lei 10.639 (BRASIL, 2003) e 11.645 (BRASIL, 2008), tornando-se componente curricular obrigatório nas escolas, existe dificuldade por parte dos professores em abordar a temática. O que justifica a reivindicação por formação inicial e continuada do corpo docente.

Embora contemplada na Base Nacional Comum Curricular - BNCC, é importante ressaltar que a inclusão da questão indígena, apenas nos conteúdos que versam sobre o período de contato e àquele que denota os aspectos populacionais de diferenciação cultural brasileira, reforçam o entendimento de que os povos indígenas fazem parte de um "nicho" cultural paralisado no tempo-espaço, quesito em que dependendo da abordagem dada ao tema, poderá ser compreendido como povos com características culturais isoladas e estanques do contexto social.

Cabe destacar ainda, que a atual BNCC foi aprovada sem que houvesse debate amplo com a sociedade, principalmente com os profissionais que atuam na área de educação. A falta de diálogo é característica dos tempos temerosos em que vivemos na atualidade. O Golpe parlamentar de 2016 que destituiu a presidenta Dilma Rousseff é imbuído de tentativas para aprovação de reformas que infringem os preceitos democráticos no país, a exemplo das reformas de previdência, trabalhista e do ensino médio.

Mesmo vivenciando tempos difíceis no país, concluímos que os povos indígenas são caracterizados como grupo social emergente ao destacarmos a luta pela terra e, ao mesmo tempo, resistentes, ao considerarmos o processo histórico, através dos etnocídios e genocídios sofridos por esses índios desde o século XVI.

O território para os povos indígenas é diferenciado porque não é apenas o espaço concreto ou absoluto criado a partir de componentes naturais e sociais. Ele é gerador de raízes e identidade, pois passa a ter uma representação de pertencimento para o grupo étnico que se utiliza desta porção. 


\section{REFERÊNCIAS}

AMORIM, P. M. de. Índios Camponeses: os Potiguara de Baía da Traição. 1970. 97p. Dissertação (Mestrado em Antropologia Social) - Universidade Federal do Rio de Janeiro/Museu Nacional, Rio de Janeiro.

ARRUTI, J. M. Emergência dos "remanescentes": Nota para o diálogo entre indígenas e quilombolas. Mana, Vol.3 n.2, p.7-38, 1997. Disponível em: <www.scielo.br>. Acesso em 10 nov 2005.

ARRUTI, J. M. A morte e vida do nordeste indígena: a emergência étnica e o fenômeno regional. Revista Estudos Históricos, vol.8 n.15, p.57-94, 1995. Disponível em: <www.cpdoc.fgv.br/revista/arq/165.pdf>. Acesso em 13 nov 2005.

ARRUTI, J. M. Agenciamentos Políticos da "mistura": Identificação étnica e segmentação Negro-Indígena entre os Pankararú e os Xocó. Estudos Afro-asiat, vol. 23 n. 2, p.215-274, 2002. Disponível em: <www.scielo.br>. Acesso em 11 nov 2005.

AZEVEDO, A. L. L. de. 'A terra somo nossa': uma análise de processos políticos na construção da terra potiguara. 1986. 286p. Dissertação (Mestrado em Antropologia Social) - Universidade Federal do Rio de Janeiro/Museu Nacional, Rio de Janeiro.

BARBOSA JUNIOR, F. de S. Os caboblos de Monte-Mór: identidade e resistência Potiguara. 2002. 66p. Monografia (Especialização em Direitos Humanos) - Universidade Federal da Paraíba, João Pessoa.

BARCELLOS, L; et al. Diversidade Paraíba: indígenas, religiões afro-brasileiras, quilombolas, ciganos. João Pessoa: GRAFSET, 2014.

BAUMANN, T. de B. Relatório Potiguara. Rio de Janeiro: Fundação Nacional do Índio, 1981.

BENJAMIM, R. E. C. O Brasil Indígena: história e cultura dos povos indígenas do Brasil. João Pessoa: GRAFSET, 2010.

BRASIL. Constituição da República Federativa do Brasil (1988). Brasília: Senado, 1989. 
BRASIL. Estatuto do Indio - Lei 6.001, 1973. Disponível em: <http://www.planalto.gov.br/ccivil_03/Leis/L6001.htm> Acesso em 25 set 2019.

BRASIL. Lei n. 11.645/2008, de 10 de março de 2008. Altera a lei n. 9.394, de 20 de dezembro de 1996, modificada pela lei n. 10.639, de 9 de janeiro de 2003, que estabelece as diretrizes e bases da educação nacional, para incluir no currículo oficial da rede de ensino a obrigatoriedade da temática. Disponível em: <http://www2.camara.leg.br/legin/fed/lei/2008/lei-11645-10-marco-2008-572787publicacaooriginal-96087-pl.html> Acesso em 10 dez 2017.

BRASIL. Ministério da Educação. Secretaria da Educação Básica. Base nacional comum curricular. Brasília, DF, 2017 Disponível em: < http://basenacionalcomum.mec.gov.br/\#/site/inicio>. Acesso em15 dez 2017.

BRASIL. Lei 10639 de 9 de janeiro de 2003. Disponível em: < http://www.planalto.gov.br/ccivil_03/leis/2003/l10.639.htm>; Acesso em 25 set 2019.

CALLAI, H. C. A Geografia e a escola: muda a Geografia? Muda o ensino? Terra Livre, n. 16, p. $133-152,2001$.

CHAUÍ, M. Brasil: Mito Fundador e Sociedade Autoritária. São Paulo: Ed. Fundação Perseu Abramo, 1989.

CIMI. Violência contra os Povos Indígenas no Brasil: Dados de 2016. Brasília: Conselho Indigenista Missionário, 2016.

CLAVAL, P. A geografia Cultural. Florianópolis: UFSC, 2001.

CUNHA, M. C. da. Política Indigenista no Século XIX. In: CUNHA, M. C. da (Org.). História dos Índios no Brasil. São Paulo: Companhia das Letras, 1992.

FAUSTO, C. Os Índios antes do Brasil. Rio de Janeiro: Ed. Jorge Zahar; 2000.

FERNANDES, J. A. De Cunhã a Mameluca: A mulher Tupinambá e o Nascimento do Brasil. João Pessoa: UFPB, 2003.

FREYRE, G. (1900-1987). Casa-grande \& Sensala: formação da família brasileira sob o regime da economia patriarcal. São Paulo: Global, 2003. 
GERLIC, S; ZOETTL, P. A. (orgs.) Índios na visão dos índios: Potiguara Salvador: Thydêwá, 2011.

IBGE. Censo Demográfico 2010: Manual do Recenseador. CD 1.09. Rio de Janeiro: IBGE, 2010.

IPEA. Texto para discussão / Instituto de Pesquisa Econômica Aplicada.- Brasília : Rio de Janeiro : Ipea, 2018.

LIEDCKE, A. R. Territorialidade e Identidade Potiguara: a atuação do Ministério Público Federal em contextos de lutas pelo reconhecimento dos direitos indígenas no vale do rio Mamanguape, Litoral Norte, PB. 2007. 178p. Dissertação (Mestrado em Sociologia) Universidade Federal da Paraíba, João Pessoa.

MARQUES, A. C. N. Fronteira étnica: Tabajara e comunidades negras no processo de territorialização do Litoral Sul paraibano. 2015. 350p. Tese (Doutorado em Geografia) Universidade Federal de Sergipe, Aracajú.

MARQUES, A. C. N. Imagens do Território Potiguara: conflitos e resistências na aldeia Três Rios, Marcação - PB. 2006. 120p. Monografia (Bacharel em Geografia) - Universidade Federal da Paraíba, João Pessoa.

MARQUES, A. C. N. Território de Memória e Territorialidades da Vitória dos Potiguara da aldeia Três Rios. 2009. 217p. Dissertação (Mestrado em Geografia) - Universidade Federal da Paraíba, João Pessoa.

MARTINS, J. S. A Chegada do estranho. São Paulo: HUCITEC, 1997.

MENDONÇA, W. M. de. Memória de nós: o discurso possível e o silêncio tupinambá nos relatos de viagem do século XVI. 2002. 298p. Tese (Doutorado em Letras) Universidade Federal de Pernambuco, Recife.

MOONEN, F. \& MAIA, L.M. Etnohistória dos Índios Potiguara: ensaios, relatórios e documentos. João Pessoa: PR/PB-SEC/PB, 1992.

MURA, F; PALITOT, E; MARQUES, A. Relatório Tabajara: um estudo sobre a ocupação indígena no litoral sul da paraíba. João Pessoa: UFPB, 2015. 
OLIVEIRA, J. P. de. “A viajem de Volta": reelaboração cultural e horizonte político dos povos indígenas no nordeste. Rio de Janeiro: Atlas das Terras indígenas no Nordeste. PETI/ Museu Nacional/ UFRJ, 2004.

PALITOT, E. M. Os Potiguara da Baía da Traição e Monte-Mór: história, etnicidade e cultura. 2005. 270p. Dissertação (Mestrado em Sociologia) - Universidade Federal da Paraíba, João Pessoa.

PERES, S. Os Potiguara de Monte-Mór e a Luta pelo Reconhecimento de seu Território. In: RICARDO, C. A. Povos Indígenas no Brasil (1996-2000). São Paulo: Instituto Sócio Ambiental, 2000.

RAFFESTIN, C. Por uma Geografia do poder. São Paulo: Ed. Ática, 1993.

RAMINELLI, R. Imagens da Colonização: A Representação do Índio de Caminha a Vieira. Rio de Janeiro: Zahar, 1996.

RIBEIRO, D. O povo brasileiro. São Paulo: Companhia das Letras, 1995.

SCHNEIDER, A. Luiz. Charles Boxer (contra Gilberto Freyre): raça e racismo no Império Português ou a erudição histórica contra o regime salazarista. Estudos históricos, vol.26 n.52, p.253-273, 2013.

STADEN, H. Duas Viagens ao Brasil. Belo Horizonte: Itatiaia, 1974.

TODOROV, T. A Conquista da América: a questão do outro. São Paulo: Martins Fontes, 2003.

VESPÚCIO, A. In: BUENO, E. Novo Mundo: As Cartas que Batizaram a América (1451 1512). São Paulo: Planeta do Brasil, 2003. 